\title{
Which infants should not receive intensive care?
}

\begin{abstract}
'Andrew was a baby born 15 weeks prematurely weighing only $1 \mathrm{lb} 12 \mathrm{oz}$ and in a state of painful deterioration almost from the start. We wanted him to be allowed to die a natural death. Andrew's story is the story of what can happen when a baby becomes hopelessly entrapped in an intensive care unit where the machinery is more sophisticated than the Code of Law and Ethics governing its use.'1
\end{abstract}

With modern care more and more infants are surviving at the 'extreme margin of human viability.' Obstetricians, paediatricians, and nurses justifiably take pride in these striking improvements in perinatal mortality. Members of the public have become accustomed to success stories about the survival of 'miracle babies'. With special skills and modern medical technology it seems that anything is possible. Unfortunately, there is a darker side to the story. For a few babies like Andrew, intensive care will fail eventually. For some others with multiple and complex abnormalities the 'miracle of survival' will be the prelude to a lifetime clouded by severe and permanent impairment. Considerable professional and lay concern, particularly among parents, about the quality of life for these impaired survivors and the effects on families has led to pleas for the selective use of intensive care. ${ }^{2}$ For most infants, treatment is continued to the limits of modern knowledge and technology. For a few, as doctors have done for generations, the prudent and compassionate course of action is to withhold or stop certain treatments in the knowledge that death and relief from suffering may result.

Decisions to withhold or withdraw intensive care (aggressive resuscitation, intermittent positive pressure ventilation, parenteral feeding, complex surgery etc.) are troubling and complex. They are particularly disturbing for the doctors and nurses who work in intensive care nurseries where their efforts normally are devoted to saving life. To allow an infant to die is to contradict the central ethos of the unit and may leave emotions in turmoil. The decisions are complex because they concern judgments that not only are medical but are moral, ethical, and legal and for which doctors have little or no formal training.

\section{How large is this problem?}

In 1973 we reported that $14 \%$ of all deaths in a large regional intensive care nursery had occurred as a result of decisions to withdraw or withhold intensive care. ${ }^{3}$ Recently we have reviewed current experience in a different nursery and the equivalent figure is $20.5 \%$. This does not mean that more babies are now being denied intensive care, but rather that there has been an overall improvement in neonatal mortality rates. Stated simply, about onefifth of all neonatal deaths or 1-2 infants for every 1000 infants born alive are being 'allowed to die'.

Three groups of infants are affected. Firstly, there are the infants korn at the very limits of viability, limits that have changed so strikingly with recent improvements in obstetric and paediatric care that it is arguable if any lower limit is a valid concept. Secondly, there are babies whose brains have been damaged by disease or complications occurring during pregnancy and birth and for whom a normal life is extremely unlikely-for example after severe birth asphyxia. Thirdly, there are infants with complex and often multiple congenital abnormalities, generally but not invariably, affecting the brain and spinal cord and who are deformed to an extent that will leave them tragically handicapped despite all that modern medical and surgical treatment can offer.

\section{How small is too small?}

Neonatal intensive care of high quality is assosiated with greatly improved survival in very low birthweight infants and the majority of such infants can look forward to normal development. Under 26 weeks' gestation ( $<800 \mathrm{~g}$ birthweight) the mortality is still high even in the best units, and the risk of handicap in the survivors is considerable, perhaps unacceptable to many parents. It seems reasonable for each nursery to develop criteria for intensive care based on and modified by experience. These might include a 'cut-off' weight below which certain treatments (for example, intermittent positive pressure ventilation) would not be used at least until the implications and options had been discussed with the parents who, after all, must primarily bear the consequences of any decision. A 'cut-off' weight for intensive care only makes sense if it remains flexible and dependent on such factors as gestational age, the state of the infant at birth, the presence and timing of complications, the parents' views and the family circumstances, and the available resources. 
While our 'cut-off' is not rigid, during the last 4 years we have ventilated only one infant under $750 \mathrm{~g}$, although all have received skilled care short of assisted ventilation (D J Lloyd, 1982, personal communication).

With future developments in care and improved techniques for the assessment of prognosis in individual infants there may be no need to consider withholding intensive care from some infants no matter how tiny, assuming of course that the staff and resources will be made available. But we are approaching the stage of gestation when extrauterine survival can be maintained only by using some form of extracorporeal artificial placenta. Almost certainly this could become possible technically, but it might be an appropriate point to 'draw the line' while we contemplate the ironies and implications of overlapping with the legal limit for abortion.

\section{How handicapped is too handicapped?}

Most infants with handicapping disorders are treated aggressively and, with rare exceptions, doctors, nurses, social workers, and parents agree on the appropriate course of action. In a number of articles we have indicated the dilemmas that can occur when doctors and families together choose to allow infants to die rather than subject them to pointless and sometimes cruel treatment. ${ }^{2}{ }^{3}$ We have been criticised for our apparent unwillingness to state criteria which would identify infants from whom we would consider withholding treatment. ${ }^{4}$ Many paediatricians would probably agree that the most important medical criterion is severe abnormality, disease, or damage to the central nervous system, especially the brain, which will have devastating consequences for development. If there is little prospect of freedom from crippling disabilities that will prevent the attainment of a personal life of meaning and quality, and a measure of independence from others, then extraordinary means to sustain or prolong life are inappropriate. Specific examples include infants with hydranencephaly, severe neural tube defects, gross hydrocephalus if complicated by infection, and chromosomal disorders such as trisomy 13 and 18 . Infants with extensive and fully documented (by clinical and imaging criteria) brain damage after asphyxia and haemorrhage might also be included. In some conditions, notably Down's syndrome with complications, there is considerable disagreement about the appropriate course of action. But decisions should not be made on 'technical' criteria alone. They must be based on accurate diagnosis and a detailed, expert, and thoughtful review of all the medical and social realities including an objective assessment of likely outcome. Above all, the views of parents (and families) should be pivotal if not paramount in seeking the 'least detrimental alternative' for the infant.

\section{Taking the decision}

Taking these decisions are supreme tests of medical leadership. They must be made by a consultant and be seen to be his or her decision, even if strongly influenced by parent and family views. They should be agreed with a colleague. They should be made only after time for reflection and review of the options and the implications both of treatment and non-treatment. They must not be arbitrary or hasty and must be seen to be widely shared, particularly with the nurses and junior doctors who are in direct and consistent contact with the baby and on whom the emotional burdens of care fall most heavily. Anyone who is uncomfortable with the decisions taken on behalf of an infant who feels that they conflict with his own sincerely held views should not be expected to participate. The doctor should be convinced that withholding or withdrawing intensive care is in the best interests of the baby and the family and should be prepared to defend the decision. Accordingly, the process of decision-making should be recorded in the infant's record.

Undoubtedly, for us as doctors, the easy way out is to treat every infant aggressively using all the lifesaving technology at our disposal. We could avoid stumbling into the moral and legal pitfalls of which philosophers and lawyers keep reminding us. We could do a fine job technically and ignore the stark realities of child and family handicap. But to pretend that there is no decision to make ' ... is an arbitrary and potentially devastating decision of default. Since families and patients must live with the problems one way or another in any case, the physician's failure to face the issues may constitute a victimising abandonment of patients and families in times of greatest need.' 3 As Ingelfinger stated ' . . . current attempts to de-mysticise and debase the status of the physician are compromising his ability to provide leadership (not exercise dictatorship) when health and life are at stake-a function that may be the most important service that the physician renders to society. 5

\section{'There ought to be a law'}

To allow an infant to die without life-saving care may be interpreted as illegal and paediatricians have felt increasingly vulnerable to accusations of murder by crusading lawyers and moralising pressure groups. On the one hand there have been calls 
for stricter interpretation of existing laws and, on the other, for new legislation that will recognise a group of 'chronically disabled' infants who can be allowed to die provided certain safeguards are met. ${ }^{6}$ Traditionally, the law has shown considerable latitude in allowing a doctor and patient (or parents in the case of an infant or young child) the discretion to decide what is in the patient's best interests. Public opinion, as far as can be judged, would also prefer to see these decisions left with doctors and families. Even some lawyers believe that the law is too blunt an instrument to deal with matters of individual conscience. While new legislation might protect paediatricians from attack by 'Right to Life' groups and the threat of prosecution in the Courts, there is the danger that it could be detrimental to the close and trusting relationships that should develop among staff and between staff and parents in an intensive care nursery. It would be absurd to claim that doctors should be allowed to practise outside the law but it must be appreciated that rigid laws are of little help in reconciling the realities of modern medicine with the individual injustices of biology. Nevertheless doctors must be accountable and act within the kind of medical and moral framework that most colleagues and the majority of the public would find acceptable. In other words, as paediatricians we have a major responsibility to ensure that the process of decision-making will stand up to the most rigorous scrutiny.

Admittedly, as with many medical decisions, much depends on trust-trust in the knowledge, judgment, and integrity of the doctors and parents in putting the infant's interests above their own. With rare exceptions this trust appears to be justified. The bonds of affection within a family are strong, even for a newly-born member, and the agony of facing up to these difficult choices are protective of the infant's rights, not only from caprice but from the unthinking application of technology. Unless we are to apply modern treatments indiscriminately, and this in my view would be irresponsible, it is difficult to see how a 'child advocate', an ethics committee, or the Courts could do any better. If choices are made openly, as is advocated, abuses should be easy to detect. Perhaps there will be fewer demands for court action if individuals or organisations that seek to interfere in the intensely private affairs of families under stress can see that the choices were considered carefully on accurate information, were shared among professionals, and were debated thoroughly between doctors and parents. Perhaps they might also consider the harm they may be doing by intrusion into family grief that is none of their business.

\section{References}

1 Stinson R, Stinson P. On the death of a baby. $J$ Med Ethics 1981; 7: 5-18.

2 Duff R S, Campbell A G M. On deciding the care of severely handicapped or dying persons: with particular reference to infants. Pediatrics 1976; 57: 487-93.

3 Duff R S, Campbell A G M. Moral and ethical dilemmas in the special care nursery. $N$ EnglJ Med 1973; 289: 890-4.

4 Sherlock R. Debate: selective non-treatment of newborns. $J$ Med Ethics 1979; 5: 139-42.

5 Ingelfinger F J. Bedside ethics for the hopeless case. $N$ Engl J Med 1973; 289: 914-5.

- Brahams D, Brahams M. R v Arthur-Is legislation appropriate? Law Society Gazette 1981; 25 November.

A G M CAMPBell Department of Child Health, University of Aberdeen, Foresterhill, Aberdeen" $A B 92 Z D$ 